* Doutor em Direito pela PUCSP Universidade Federal da Grande Dourados - UFGD

E-mail: jamesheim@ufgd.edu.br

**Universidade Federal da Grande Dourados - UFGD

E-mail: suzanaheim@ufgd.edu.br

\section{O Sistema de Cadastro e Prestação de Contas como Mecanismo da Gestão Pública nas Fundações Privadas Visando Transparência Administrativa}

\author{
The System of Registration and Accountability \\ as A Mechanism of Public Management in Private \\ FOUNDATIONS FOR ADMINISTRATIVE TRANSPARENCY
}

James Gallinati Heim* Suzana Toshimi Furuia Tsukagoshi Gallinati Heim**

Como citar: HEIM, James Gallinati. HEIM, Suzana Toshimi Furuia Tsukagoshi Gallinati. O sistema de cadastro e prestação de contas como mecanismo da gestão pública nas fundaçções privadas visando transparência administrativas. Revista do Instituto de Direito Constitucional e Cidadania, Londrina, v. 3, n. 2, p. 79-92, jul/dez. 2018.

https://doi.org/10.48159/revistadoidcc.v3n2.heim.heim

Resumo: No Brasil, o terceiro setor utiliza-se das pessoas jurídicas do tipo fundação como modelo de organização mais adequado para instituir parcerias com o Estado, no sentido de implantar políticas públicas nas mais diversas áreas, assumindo uma postura moderna de gerenciador, através dos mais diversos órgãos da administração pública. As fundações na consecução de seus objetivos se utilizam de recursos públicos e esse fato, impõe às mesmas a necessidade da prestação de contas para com a sociedade, visando transparência de seus atos e uma postura ética nas suas ações. Assim sendo, quando são oriundas do setor privado, a fiscalização das mesmas fica sob o controle do Ministério Público. Atualmente, por força da legislação a manifestação deste controle se materializa através do Sistema de Cadastro e Prestação de Contas-SICAP que tem por finalidade demonstrar a prestação de contas das fundações. No presente estudo, verificouse do potencial do Sistema de Cadastro e Prestação de ContasSICAP como um instrumento de transparência nas informações prestadas por uma fundação privada da Comarca de DouradosMS. Com a análise dos documentos contábeis exigidos para preenchimento do Sistema de Cadastro e Prestação de ContasSICAP, por entrevistas e por uma análise detalhada do sistema, realizou-se um estudo de caso, no qual afirmarmos que o Sistema de Cadastro e Prestação de Contas-SICAP é um instrumento de informação jurídico-contábil hábil para dar um retrato idôneo da imagem econômico-financeira de uma fundação privada.

Palavras-chave: Fundações privadas. Transparência e Ética. 
Gestão pública. SICAP.

Abstract: In Brazil, the third sector uses legal entities of the foundation type as a model of organization more appropriate to establish partnerships with the State, in the sense of implementing public policies in the most diverse areas, assuming a modern posture of manager, through the most diverse public administration bodies. The foundations in the accomplishment of its objectives are used of public resources and this fact, imposes to them the necessity of the accountability towards the society, aiming at transparency of its acts and an ethical stance in its actions. Thus, when they come from the private sector, their supervision is under the control of the Public Prosecutor. Currently, by virtue of legislation, the manifestation of this control is materialized through the System of Registration and Provision of Accounts-SICAP, whose purpose is to demonstrate the accountability of foundations. In the present study, it was verified the potential of the System of Registration and Provision of Accounts-SICAP as an instrument of transparency in the information provided by a private foundation of the DouradosMS County. With the analysis of the accounting documents required to complete the System of Registration and Provision of Accounts-SICAP, through interviews and a detailed analysis of the system, a case study was carried out, in which we affirm that the System of Registration and Provision of Accounts-SICAP is a legal and accounting information tool capable of giving an appropriate picture of the economic and financial image of a private foundation.

Kywords: Private Foundations. Transparency and Ethics. Public Management. SICAP. 


\section{INTRODUÇÃO}

O presente estudo tem por objetivo apresentar como a gestão pública brasileira faz uso da contabilidadee seus instrumentos de controle como mecanismo capaz de dar transparência para as ações praticadas por uma fundação privada na Comarca de Dourados-MS, e que concentra basicamente a maioria de suas atividades prestando serviços para a Universidade Estadual de Mato Grosso do Sul-UEMS. A fundação em questão é uma promotora de serviços públicos, portanto enquadram-se nas fundações que deverão fazer a prestação de contas para com a sociedade. Resolvemos encarar essa pesquisa devido ao fato de estarmos na condição de assessorar juridicamente aos responsáveis legais pelos controles contábeis e pela elaboração dos instrumentos de transparência administrativa em relação ao Sistema de Cadastro e Prestação de Contas-SICAP.

Ao longo do tempo o Estado cria a necessidade de instrumentos de acompanhamento das atividades desenvolvidas pelas fundações que recebem recursos públicos, cobrando-se um desempenho ético e transparência nas informações oferecidas à sociedade. Nesse contexto, dos instrumentos de transparência identificados na doutrina norte-americana conhecido como accountability, a qual se caracteriza como uma prestação de contas e a demonstração dos resultados obtidos, considerados como elementos indispensáveis para dar credibilidade a uma governança coorporativa. A título de informação, governança coorporativa apesar de ser um conceito oriundo das empresas que atuam no mercado, tem sido estendido também às instituições não lucrativas. Com isso, as fundações também estão sendo obrigadas a fazerem suas prestações de contas, para os devidos fins e aos órgãos fiscalizadores. Portanto, iremos salientar o papel de uma dessas prestações de contas, utilizadas pelas fundações, que é conhecida por Sistema de Cadastro e Prestação de Contas-SICAP. Este instrumento de prestação de contas é utilizado pelo Ministério Público de diversos Estados membros brasileiros, com o intuito de fiscalizar e acompanhar o desenvolvimento das atividades das fundações, dando ênfase ao fato de que nasce por meio de um convênio com a Fundação Instituto de Pesquisas Econômicas-FIPE.

O Sistema de Cadastro e Prestação de Contas-SICAP busca avaliar o patrimônio e a finalidade das fundações. O controle de patrimônio se faz com o acompanhamento financeiro do dia-a-dia da fundação, por meio de relatórios contábeis. Por outro lado, o controle de finalidade se faz pelo acompanhamento das atividades desenvolvidas pela fundação de seus objetivos. Com isso, pretende-se fazer uma análise deste sistema como um instrumento de accountability das fundações, em particular, da fundação que atua em Dourados-MS, dando apoio à pesquisa, ensino e extensão junto a Universidade Estadual de Mato Grosso do Sul, verificando as informações disponibilizadas pelo sistema e levantando informações sobre a fundação.

\section{CONSIDERAÇÕES GERAIS SOBRE AS FUNDAÇÕES}

Atualmente, despertou-se o interesse de se constituírem pessoas jurídicas e entidades de interesse social com a finalidade de atuar junto ao Estado para descentralizar as ações ligadas à 
implementação de ações que visam realizar políticas públicas, nas mais diversas áreas como saúde, educação, trabalho, lazer, meio ambiente, cooperativismo, serviços sociais, etc. Seguindo esta linha de pensamento, este trabalho é uma proposta de entender os aspectos relevantesdo papel desempenhado por uma fundação, voltada a educação e os reflexos da sua responsabilidade patrimonial. Para tanto, precisamos fazer algumas considerações de cunho geral sobre fundação, onde iremos abordar conceito e características essenciais de uma fundação, conforme a seguir.

Inicialmente, devemos entender como sendo fundação toda a pessoa jurídica de direito privado prevista nos termos do artigo 44 do Código Civil brasileiro, compreendida como um complexo de bens destinados a buscar fins sociais e determinados, ou seja, são entidades de cunho econômico de caráter impessoal. Assim sendo, as fundações tem seu fundamento econômico nas doações feitas pelos seus fundadores. Em outras palavras, as fundações são constituídas por um patrimônio destinado a um fim de utilidade ou de interesse público, seja moral, científico, religioso, etc. reconhecido como tal em nosso direito positivo, e muitas das vezes o seu fim social escolhido ostenta um papel valoroso e de extremo relevo dentro das sociedades em que se insere prestando serviços sociais e de utilidade pública diretamente a todos aqueles que necessitam.

A criação de uma fundação será feita por ato de seu fundador, através de escritura pública ou testamento, com a dotação especial de bens livres, especificando o fim a que ela se destina, e declarando os aspectos relativos a sua gestão eforma de administração. Vale dizer, os bens são doados por uma pessoa natural ou jurídica de direito privado ou público para um fim social devidamente escolhido e, depois do ato constitutivo, torna-se imutável esta situação jurídica, de sorte que a finalidade a que se destina passa a ser permanente. Em tempo, podemos relacionar as cinco principais características das fundações: a) a finalidades e os fins; b) a origem e a forma de criação; c) o patrimônio; d) um modo de administração; e e) o velamento do Ministério Público. Neste trabalho, temos particular interesse no modo de administração ou a organização administrativa que é característica basilar do ente fundacional, pois, ao vincular-se um patrimônio ao fim, verificou-se, a necessidade de diferenciar-se os instituidores dos administradores e separar esses órgãos autônomos, mas subordinados, cabendo-lhes: deliberar e traçar metas e diretrizes, como função do conselho curador ou deliberativo; executar função do conselho administrativo ou executivo, e o de controlar que internamente é função do conselho fiscal.

Finalizamos, tratando da constituição de uma fundação que se dá através do seu registro para que ela adquira personalidade jurídica e que é realizado pelo seu fundador no Cartório de Registro Civil das Pessoas Naturais. Podemos dividir em quatro fases o processo de constituição e personalização de uma fundação, que são: $1^{\mathrm{a}}$ ) da dotação; $2^{\mathrm{a}}$ ) da elaboração do estatuto social; $3^{\text {a }) ~ d a ~ a p r o v a c ̧ a ̃ o ~ d o ~ e s t a t u t o ~ s o c i a l ; ~ e ~} 4^{\text {a }}$ ) do registro no órgão competente. Como característica principal das fundações de direito privado, cabe ressaltar o papel desempenhado pelo Ministério Público como ente estatal incumbido por lei, para observar o estatuto social e acompanhar, intervir e fiscalizar a atuação das fundações durante sua existência. (PAES, 2013). 


\section{ADMINISTRAÇÃO E CONTROLE DOS ATOS DA FUNDAÇÃO}

Como foi ressalvado anteriormente, as fundações possuem um papel relevante dentro da sociedade, tendo na atualidade um papel de verdadeira parceira do Estado, e identificada como forma jurídica de organização do denominado Terceiro Setor. Estas independentemente da forma como são instituídas tem por meta proporcionar benefícios a uma comunidade, ou como no caso em tela, para uma instituição pública de ensino superior. No dia-a-dia das fundações cabe ao administrador fundacional dirigir a organização de forma a atender à coletividade, seguindo os propósitos estatutários. A administração fundacional como a maioria das atividades inseridas no Terceiro Setor tem no dirigente fundacional a pessoa que responde que responde pelos atos da fundação no Ministério Público e os demais órgãos de fiscalização responsáveis pela fundação, e via de regra, são pessoas envolvidas sem o compromisso financeiro para executar suas tarefas, ou seja, são marcadas pelo senso de voluntarismo, independente da função ocupada na organização. Isto se deve ao fato dos dirigentes fundacionais apesar de não ser vedada a sua remuneração, para a entidade não perder principalmente algumas vantagens fiscais, tem amparada pela legislação a sua não remuneração (SZAZI, 2003). No entanto, as fundações irão fazer a gestão, de recursos em busca de resultados, e para tanto, necessitam de um planejamento estratégico e orçamentário, buscar fontes de recursos e ter à sua disposição recursos humanos para a sua execução e controle (FALCONER, 1999).

É oportuno, afirmar que sem um planejamento que defina as metas e objetivos, gere planos de ação e avalie os resultados não será possível ter uma organização, inclusive é preciso demonstrar que reúne as condições de eficiência e eficácia como instituição, sob penade comprometer o seu processo contínuo e operacional de alcançar os objetivos propostos pelo planejamento estratégico. O que nos leva a necessidade da elaboração de relatórios gerenciais, assim como ocorre em qualquer organização é fundamental para a mensuração dos objetivos propostos da organização e seu atendimento. É indispensável estabelecer as formas pelas quais as fundações possam ser avaliadas, quantitativamente e qualitativamente, partindo sempre da missão fundacional e de seus objetivos. Ainda, dentro do planejamento da fundação não pode ser esquecido o planejamento orçamentário que envolve uma série de aspectos econômicos e contábeis, e eles serão tratados no tópico específico das fundações (ROSSI JÚNIOR, 2001).

Agora abriremos um parêntesis, no que tange a administração fundacional, que tratará dos direitos de dirigentes de fundações, quanto a sua representatividade na frente da fundação, que podem ser resumidos em dez itens, que são:

a) de representação junto a todos os órgãos públicos, junto ao Ministério Público e especialmente junto ao Poder Judiciário, em todos os atos e causas em que a fundação tenha interesse;

b) de serem ouvidos em todos os órgãos públicos, em especial na Promotoria de Justiça de Fun- 
dações, devendo mesmo ter data e horário para expor suas pendências, também em harmonia com sua agenda;

c)de serem atendidos dentro do horário de expediente, em qualquer entidade pública e em especial nos órgãos públicos que prestem a fiscalização pela fundação que dirige;

d) de reivindicar tudo que a lei permita, em qualquer instância ou foro da administração da justiça;

e) de postular em Juízo, inclusive e, se for o caso, contra o próprio Ministério Público;

f) de contratar funcionários, sem ser confundido com a entidade, inclusive no tocante à responsabilidade empregatícia, bem como demiti-los, quando conveniente;

g) de deliberar em nome da fundação interna e, externamente, sempre, que o estatuto social assim o permitir;

h)de decidir em nome da fundação, advindo das decisões todo o respeito e todas as consequências que a lei lhe atestar;

i) de tomar as contas de todos os funcionários da entidade, quando assim entender;

j) de tomar as contas da Diretoria Executiva, examinar balanços, etc., sempre que o cargo pertencer ao Conselho Curador ou Conselho Fiscal. (RAFAEL, 1997)

Ainda é digno de registro,que as fundações contam com alguns órgãos de sua estrutura administrativa que auxiliam o gestor fundacional que são divididos em três: Conselho diretor - órgão executivo e responsável pela gerência das atividades (destinação patrimonial, representatividade judicial e regulamentação interna); Conselho fiscal - baseada no artigo $4^{\circ}$ da Lei n. ${ }^{o}$ 9790/99, o conselho fiscal é responsável pela fiscalização e auditoria contábil, bem como dos relatórios gerenciais e pelo controle patrimonial, procurando coibir fraudes, erros e crimes; Conselho deliberativo - responsável pela elaboração de diretrizes da fundação, no que tange ao aspecto patrimonial, de finalidade e de eleição dos dirigentes. (DINIZ, 2003).

\section{SISTEMA DEINFORMAÇÃOCONTÁBIL DA FUNDAÇÃO}

O Sistema Gerencial de Informação (SIG) de uma empresa é formado por vários subsistemas que o alimentam de diversas informações, dentre eles, temos o Sistema de Informação Contábil (SIC), este se transforma no responsável pelos números gerenciais capazes de contribuírem com as tomadas de decisão por parte dos gestores, do ponto de vista financeiro e econômico. Por isso, que esse referido sistema agrega todos os dados das operações econômicas, financeiras e contábeis da empresa. A intenção do sistema de informação contábil é proporcionar a alta administração informações tempestivas e úteis tanto a usuários internos, quanto a externos à organização. (HENDRIKSEN, VAN BREDA, 1999). 
De fato são muitos os usuários das informações contábeis, entretanto não há consenso sobre os tipos de informações são consideradas mais relevantes. Recentemente o Comitê de Pronunciamentos Contábeis-CPC passou a considerar o usuário acionista como principal e mais complexo usuário da informação contábil. Logo, observamos uma tendência à padronização dos relatórios contábeis a esse usuário. Temos quando a contabilidade, pela realização de seu trabalho, não apresentando-se a terceiros: usuários e dependentes de forma íntegra e confiável, não sendo estas fornecidas com base no conhecimento técnico e na ética, poderão trazer sérios problemas, como: ao empresário contratante dos trabalhos, de informações que poderão levá-lo a tomar decisões prejudiciais à empresa; aos sócios, acionistas ou proprietários, prejuízos na avaliação de seus patrimônios; aos credores ou fornecedores de créditos, prejuízos pelo eventual não-recebimento de seus direitos; ao País, pelo não-recebimento de tributos, o que causará danos a todos de maneira geral (FRANCO, 1993).

Ainda sob uma visão genérica de empreendimento, outro grande problema do segmento empresarial no Brasil e que também atinge as fundações é a questão da transparência em relação às demonstrações contábeis, pois nem todas as empresas são obrigadas à publicação de seus demonstrativos financeiros em jornais. E esse é o caso das fundações privadas, cabendo a elas apenas a obrigações de prestar contas ao Ministério Público, tolhendo a sociedade de tomar conhecimento dessas informações. Além de prejudicar a análise dos dados por parte da sociedade. A lei n. ${ }^{\circ}$ 6404/1976, conhecida como a Lei das sociedades anônimas, alterada parcialmente pelas leis n. ${ }^{\circ} 11638 / 2008$ e n. ${ }^{\circ} 11941 / 2009$ definem a contabilidade para as atividades empresariais e a princípio a contabilidade das fundações segue o mesmo padrão. Além de se subordinarem a lei referida as fundações seguem os princípios de contabilidade, estabelecidos pelo Conselho Federal de Contabilidade e Comitê de Pronunciamentos Contábeis-CPC. (GONÇALVES, 2000)

$\mathrm{Na}$ verdade, mesmo não tendo um caráter lucrativo, existe a necessidade da fundação auferir um resultado econômico final positivo, onde receitas superem despesas, pois é fundamental para que haja uma boa administração financeira da fundação, onde novas oportunidades são possíveis com a perspectiva de reinvestimentos.

Finalizando o tópico, cabe salientar aqui que as fundações não possuem a obrigatoriedade de terem seus números analisados por especialistas externos, denominados de auditores, pois a auditoria externa só é exigida para as empresas constituídas sob a forma de sociedades anônimas, instituições financeiras, seguradoras, etc., definidas pela Lei n. ${ }^{\circ}$ 6040/1976. Apenas quando o Ministério público na condição de órgão vigilante e responsável resolver solicitar como um complemento às demonstrações contábeis tradicionais, e essa solicitação acontece geralmente de acordo com o porte da fundação. O Ministério Público se utiliza de um instrumento de coleta de dados e informações no velamento das fundações denominado de Sistema de Cadastro e Prestação de Contas-SICAP. A seguir apresentamos o referido sistema que é utilizado para atender às exigências do Ministério Público. 


\section{SISTEMAS DEACCOUNTABILITYEM ORGANIZAÇÕES}

Encontraremos no sítio do Instituto Brasileiro de Governança Corporativa-IBGC o significado de accountability como sendo parte integrante do tripé da governança corporativa, juntamente com a transparência e a equidade. Entretanto o termo se traduz como sendo a responsabilidade do agente tanto pela tomada de decisões como por sua implementação, pela obrigação de prestar contas tanto por ações como por omissões. Implica, ao longo do cumprimento de sua missão, no contexto amplo de exigências originadas de uma gama variada de grupos sociais (BRANCO, 2000).

Então temos a expressãoaccountabilitycomo a responsabilidade da prestação de contas da atuação dos representantes na gestão dos gastos públicos, enquanto governo, assim como em outras organizações que utilizam desses recursos, como é o caso das Organizações Não GovernamentaisONG's e fundações. E quanto às obrigações constituídas para dirigentes das fundações, em relação à prestação de contas, como ficou esclarecido nos tópicos anteriores, são enviadas ao Ministério Público. Portanto, é relevante neste momento citar os deveres dos dirigentes fundacionais e que são em número de treze:

1) deverá cuidar dos atos de direção da fundação para que seus livros de Atas, bem como os livros contábeis, estejam sempre devidamente registrados nos órgãos competentes, com regular autorização e/ou ciência da Promotoria de Justiça de Fundações;

2) de realizar a convocação, por escrito e no prazo estatutário previsto, de todos os integrantes dos órgãos diretivos para as reuniões ordinárias;

3) de observar, quando do início das reuniões, da existência de quorum mínimo previsto estatutariamente, sempre em razão da matéria a ser deliberada que, como é sabido, pode ter variação para este ou aquele tema, na medida de sua importância;

4) de Providenciar, após autorização ou ciência ao Ministério Público, o competente registro de todas as atas lavradas (com um resumo de cada tema debatido) no Cartório do Registro Civil das Pessoas Jurídicas, em especial, quando o texto transcrito, aprovado e regularmente assinado, operar efeitos perante terceiros;

5) de enviar, até 31 de dezembro de cada ano, plano das atividades para o ano seguinte;

6) quando do envio do balanço anual à Promotoria de Justiça Cível de Fundações até 31 de abril de cada ano, o documento deve seracompanhado de deliberação do Conselho Curador, bem como parecer elaborado pelo Conselho Fiscal, se estatutário (quando existir esse órgão);

7)de informar, anualmente, quais pessoas (com respectivos domicílios) são componentes dos órgãos diretivos da fundação, bem como eventual vacância de algum cargo;

8) de relacionar, também quando da prestação anual de contas, eventuais remunerações pagas a integrantes de Superintendências, quando possível estatutariamente, informando a prestação de serviços ou execução de trabalhos efetivamente realizados;

9) de prestar informar quanto ocorrer à eventual acumulação provisória de cargos por integrantes dos órgãos diretivos da fundação; 
10) de informar quanto à existência de órgão auxiliar da administração superior, declinando a nomenclatura e designação do cargo, o nome e qualificação do ocupante, bem como a natureza do contrato efetivado;

11) de elaborar relatório completo sobre eventuais recebimentos de contribuições de conteúdo econômico entregues pela mantenedora, afiliada ou congênere;

12) de juntar certidão de Promotoria de Justiça de Fundações local (de outra comarca ou Estado), quando a fundação operar em outras sedes;

13)de apresentar, quando solicitado, documento legal de fiscalização de outros órgãos públicos, sempre que a fundação, pela natureza e fins de suas finalidades, ficar à mercê de mais de um ente fiscalizador. (RAFAEL, 1997)

Dessa maneira, entendemos que o termo accountabilitynão compreende apenas aspectos de contabilidade, mas é uma prestação de contas mais ampla, que engloba aspectos de gestão e de resultados ofertados à sociedade. Está intimamente relacionada a planejamento com comprometimento de recursos em tela, além dos elementos legais para o cumprimento e prestação de contas. Na sequencia destacamos as demonstrações contábeis apresentadas quando da prestação de contas efetuada ao Ministério Público: a) Balanço Patrimonial; b) Demonstração de Resultado do Exercício-DRE; c) Demonstração de Valor Adicionado-DVA; d) Demonstração de Lucros ou Prejuízos Acumulados (COELHO, 2013).

\section{SISTEMA DE CADASTRO E PRESTAÇÃO DE CONTAS-SICAP}

No ano de 2000, foi criado o Centro de Estudos de Fundações e Entidades de Interesse Social-CEFEIS, na Fundação Instituto de Pesquisas Econômicas-FIPE, que veio preencher uma lacuna nas pesquisas sobre economia das instituições sem fins lucrativos e do Terceiro Setor. O referido centro foi criado com a missão de fomentar a pesquisa e estudar os aspectos sociais e econômicos das instituições sem fins lucrativos, organizadas sob a forma jurídica de fundação bem como as entidades de interesse social e coletivo no Brasil, produzindo e divulgando conhecimento relevante, contribuindo para o fortalecimento institucional do Terceiro Setor e das instituições nele inseridas. E como objetivos oCentro de Estudos de Fundações e Entidades de Interesse SocialCEFEIS apresentou os seguintes: a) de contribuir para a promoção dagovernança responsável, para atransparênciae para disseminar a prática da responsabilidade social, nas/das instituições sem fins lucrativos; b) de contribuir para a expansão do conhecimento sobre o setor das instituições não lucrativas e para a busca de suas melhores práticas; e, c) de contribuir para a visibilidade e legitimidade das atividades desenvolvidas por essas instituições, de forma agregada, incentivando e fomentando a pesquisa sobre o setor. (CEFEIS, 2014)

Nesse sentido é que foi desenvolvida ideia orientadora do SICAP, e que efetivamente trata-se do Sistema de Cadastro e Prestação de Contas, e que passou a ser o instrumento de coleta de dados e informações, utilizado por diversosMinistérios Públicosestaduais, no velamento das fundações, conforme dispositivo legal previsto no artigo 66 do Código Civil brasileiro, Lei n. ${ }^{\circ}$ 10406, de 10 de janeiro de 2002, e que era anteriormente, previsto no artigo 26 da Lei n. ${ }^{\text {o } 3071, ~}$ 
de 01 de janeiro de 1916, e das entidades de interesse social.O Sistema de Cadastro e Prestação de Contas-SICAP tem por objetivo, também, o provimento de dados para a elaboração de estudos e estatísticas e a disponibilização de informações econômico-sociais das instituições sem fins lucrativos. Os dados coletados pelo Sistema de Cadastro e Prestação de Contas-SICAP constituem expressivos insumos para atendimento de seis necessidades, que são as seguintes:

1) a da criação de um cadastro nacional de fundações;

2) a da adoção de procedimentos uniformes para a prestação de contas;

3) a da sistematização dos dados coletados;

4) a de cumprimento da legislação aplicável;

5) a de estudos técnicos de natureza estatística;

6) a de ética e transparência na atuação dos diversos agentes e atores do Terceiro Setor. (CEFEIS, 2014)

Com a instituição do referido sistema, asfundações de direito privadolocalizadas nos Estados brasileiros, passaram a utilizar o Sistema de Cadastro e Prestação de Contas-SICAP na prestação de contas anual ao Ministério Público. Nesse sentido, o Sistema de Cadastro e Prestação de Contas-SICAP passou a ser oinstrumento de coleta de dados e informações, aceito pelosMinistérios Públicos estaduais,conveniadoscom aFundação Instituto de Pesquisas Econômicas-FIPE, no velamento das fundações e entidades de interesse social. Com isso as Instituições dos seguintes Estados brasileiros se utilizam do programa Sistema de Cadastro e Prestação de Contas-SICAP ao prestar contas ao Ministério Público: Estados conveniados - AC, AL, AM, CE, BA, ES, MA, MG, MS, MT, PA, PB, PE, PI, PR, RJ, RN, RR, RS, SC, SP e TO.

anteriormente, Vamos entender a sistemática da prestação de contas exigidas pelos Ministérios Públicos estaduais, utilizando a figura elaborada pelo Ministério Público do Paraná: 


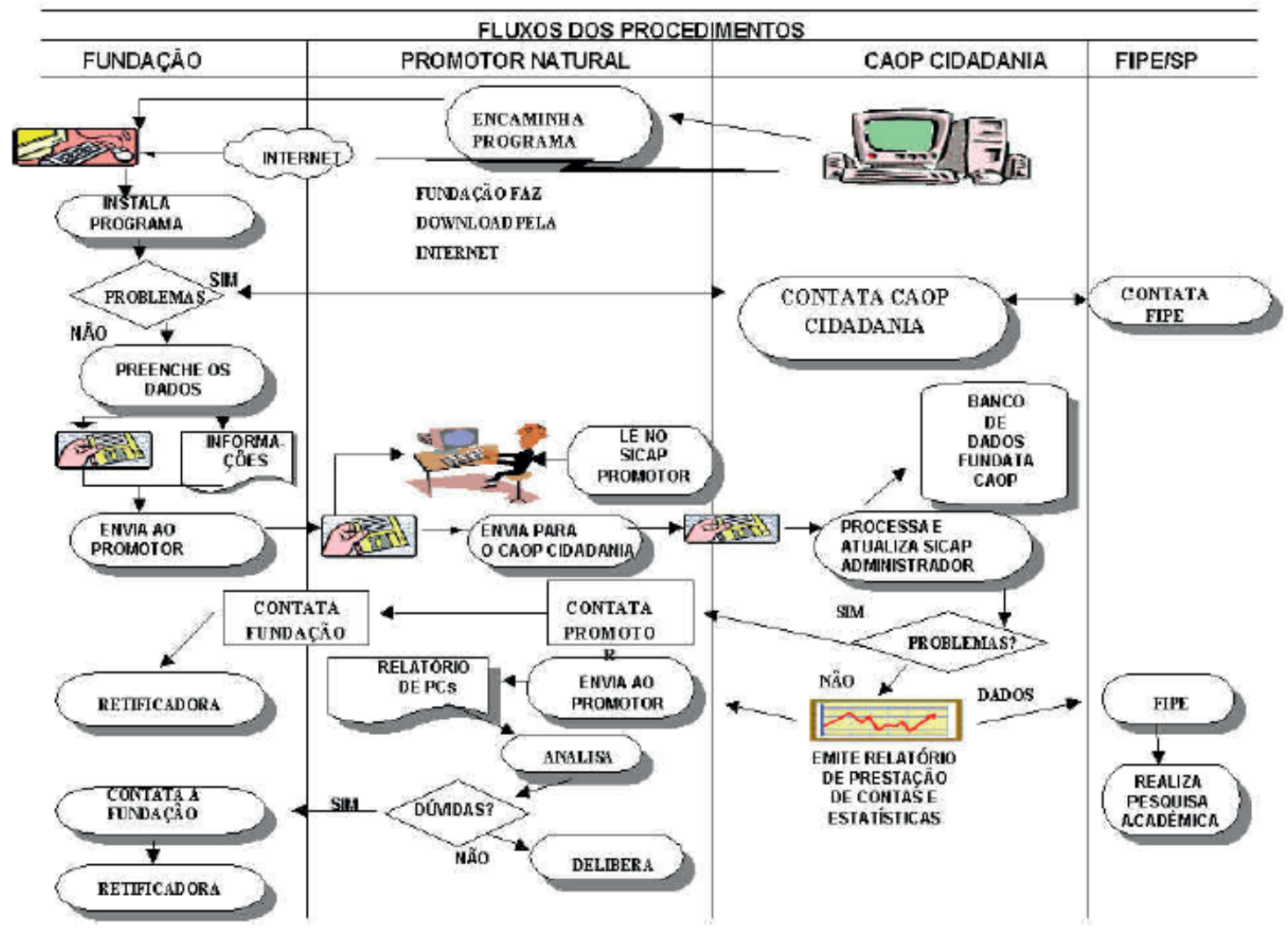

Figura 3 - Sistemática de prestação de contas anual das fundações

Fonte: Ministério Público do Estado do Paraná

\section{PROCEDIMENTOS METODOLÓGICOS}

Cada estudo tem seu objetivo definido, todavia os propósitos de pesquisa podem ser aplicáveis a uma série de finalidades. Neste trabalho foram utilizadas várias técnicas de pesquisa para se atingir os objetivos, sendo feita uma revisão bibliográfica sobre Terceiro Setor, fundações e accountability. Na sequência foi efetuada uma análise do Sistema de Cadastro e Prestação de Contas-SICAP. Adotou-se para a elaboração dessa, a pesquisa do tipo qualitativa pois não busca enumerar ou medir eventos, e ainda não emprega instrumental estatístico para análise dos dados (GODOY, 1995). E em relação à classificação da pesquisa quanto aos objetivos, de acordo com Gil (2006b) adotamos a pesquisa do tipo exploratória com estudo de caso.

\section{CONSIDERAÇÕES FINAIS}

Este trabalho adentrou nos limites do campo de atuação do Terceiro Setor, que atualmente no Brasil, contempla um grande número de organizações dentre as quais merece destaque as fundações. Depois de fazer uma breve explanação sobre o seu significado, características, regulamentação, administração e controle, abordamos o mecanismo que cuida da prestação de resultados à sociedade. Sem dúvidas, é preciso tratar do Ministério Público que é o agente responsável por acompanhá-las e fiscalizá-las. 
Isto posto, quando se trata da mensuração dos objetivos propostos por uma fundação identificando sua missão e objetivos, abrimos um leque de aspectos que iniciam com o planejamento, coordenação, execução e controle, neste último, estão envolvidos aspectos contábeis e que foram tratados em tópico específico sobre a contabilidade das fundações. E nesse sentido foi preciso tratar do Sistema de Cadastro e Prestação de Contas-SICAPque é o instrumento hábil para coleta de todos os dados e informações, relativos ao exercício de atividades por uma fundação, que são representadas por inúmeras transações responsáveis pela movimentação dos recursos financeiros, portanto estamos falando de controle das contas, do patrimônio que exige um rigoroso sistema de registro das operações por parte dos gestores. Nas ciências contábeis, esta matéria quando objeto de exame mais acurado é feita através de perícias contábeis e auditorias internas e externas que geram despesas de vulto econômico razoável.

Ficou claro que o papel desempenhado pelo Sistema de Cadastro e Prestação de Contas-SICAP tem por objetivo, realizar uma concentração de dados através de um extenso e complexo formulário digitalizado que será responsável por permitir uma elaboração de uma análise concreta das informações econômico-sociais das fundações sem fins lucrativos. Os dados coletados pelo Sistema de Cadastro e Prestação de Contas-SICAP constituem expressivos insumos para atendimento das necessidades, de criação de um cadastro nacional de fundações, da adoção de procedimentos uniformes para a prestação de contas, da adoção de procedimentos uniformes para a prestação de contas, da adoção de procedimentos uniformes para a prestação de contas, da adoção de procedimentos uniformes para a prestação de contas, da sistematização dos dados coletados, de cumprimento da legislação aplicável, de estudos técnicos de natureza estatística, de ética e transparência na atuação dos diversos agentes e atores do Terceiro Setor.

Portanto, podemos afirmar que o Sistema de Cadastro e Prestação de Contas-SICAP é um instrumento de informação complexo, de compreensão técnica de grau médio e hábil para dar um retrato detalhado e idôneo da imagem de uma fundação privada para responder os questionamentos sobre a regularidade e o atendimento às disposições legais exigidas na prestação de contas a que estão submetidas.

\section{REFERÊNCIAS}

ALONSO, Feliz Ruiz; LÓPEZ, Francisco Granizo; CASTRUCCI, Plínio de Lauro. Curso de ética em administração. 1. ed. 2. reimpr. São Paulo: Atlas, 2008.

ASSOCIAÇÃO BRASILEIRA DE NORMAS TÉCNICAS. NBR 10520: informação e documentação - referências - apresentação. Rio de Janeiro: ABNT, 2002.

CEFEIS. CENTRO DE ESTUDOS DE FUNDAÇÕES E ENTIDADES DE INTERESSE SOCIAL. (2013). Disponível em: http://www.fundata.org.br/cefeis.htm. Acesso em: $17 \mathrm{dez}$. 2013. 
CERVO, Amado L.; BERVIAN, Pedro A. e DA SILVA, Roberto. Metodologia científica. São Paulo: Pearson Prentice Hall, 2007.

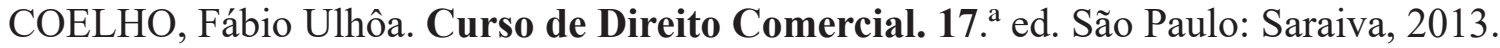

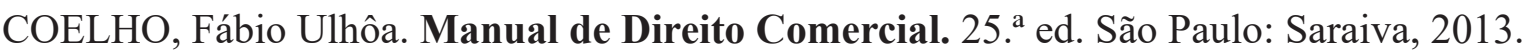

CRCMS. CONSELHO REGIONAL DE CONTABILIDADE DE MATO GROSSO DO SUL. Os Princípios de Contabilidade, as Normas Internacionais de Contabilidade e o Código de Ética Profissional do Contabilista. (2013). Disponível em: http://www.crcms.org.br/. Acesso em 12 jan. 2014.

DINIZ, Gustavo Saad. Direito das fundações privadas: teoria geral e exercício de atividades econômicas. 2. ed. Porto Alegre, Síntese, 2003.

FABRETTI, Láudio Camargo. Contabilidade Tributária. 11 ed.São Paulo: Atlas, 2009.

FALCONER, Andrés Pablo. A proposta do Terceiro Setor: um estudo sobre a construção do papel das organizações sem fins lucrativos e de seu campo de gestão. Centro de estudos em Administração do Terceiro Setor (CEATS), 1999. ). Disponível em: http://www.ceats.org.br/. Acesso em 27 jan. 2014.

FIGUEIREDO, Sandra e CAGGIANO, Paulo César. Controladoria: teoria e prática. $4^{\mathrm{a}}$. Ed. São Paulo: Atlas, 2008.

FRANCO, Hilário. Contabilidade Geral. 23. ed. São Paulo: Atlas, 1996.

FREITAS, Newton. Dicionário Oboé de Finanças. 14. ${ }^{a}$ ed. Fortaleza: Imprensa Universitária, 2004.

GIL, Antonio Carlos. Métodos e técnicas de pesquisa social. São Paulo:Atlas, 2006a.

GODOY, Arilda S. Introdução à pesquisa qualitativa e suas possibilidades. In: Revista de Administração de empresas, v.35, n.2. Mar./Abr. 1995, p.57-63.

GONÇALVES, Rosana Carmen Meiroz Grillo (2000). Introdução e definição de sistemas de informação e informações contábeis sob perspectiva de seus usuários. Ribeirão Preto, USP, 2000. (Apostila).

HENDRIKSEN, Eldon S.; BREDA, Michael F. Van.Teoria da contabilidade. São Paulo: Atlas, 1999.

MARCONI, Marina de Andrade; LAKATOS, Eva Maria. Técnicas de pesquisa: planejamento e execução de pesquisas, amostragens e técnicas de pesquisa, elaboração, análise e interpretação de dados. São Paulo: Atlas, 2007.

OLIVEIRA, Antonio Benedito Silva. Método da pesquisa Contábil. São Paulo: Atlas, 2011.

PADOVEZE, Clóvis Luís. Contabilidade Empresarial. 7. ed. São Paulo: Atlas, 2010. 
RICHARDSON, Roberto Jarry. Pesquisa social: métodos e técnicas. São Paulo: Atlas, 1999.

PAES, José Eduardo Sabo. Fundações, Associações e Entidades de Interesses Sociais. Aspectos Jurídicos, administrativos, contábeis, trabalhistas e tributários. $8^{\mathrm{a}}$. ed. Rio de Janeiro: Forense, 2013.

RAFAEL, Edson José. Fundações e direito: 3º. Setor. São Paulo: Melhoramentos, 1997.

ROSSI JÚNIOR, Luiz Rodovil. A Gestão para resultados como ferramenta administrativa nas organizações do Terceiro Setor, Ano 4, n 2. Mai 2001. Disponível em: <http://integracao. fgvsp.br/ano4/2/administrando.htm>. Acesso em:19 fev. 2014.

SÁ, Antônio Lopes de \& SÁ, A.M. Lopes de. Dicionário de Contabilidade. São Paulo: Atlas. 1995.

SCHNORRENBERGER, Darci; LUNKES, Rogério João. Controladoria: Na Coordenação dos Sistemas de gestão. São Paulo: Atlas, 2009.

SEVERINO, Antônio Joaquim. Metodologia do trabalho científico. São Paulo: Cortez, 2007.

SZAZI, Eduardo. Terceiro Setor: regulação no Brasil. 3 ed. São Paulo: Petrópolis, 2003.

TORRES, Leandro Vila. O sistema de Cadastro e Prestação de Contas (SICAP) como instrumento de accountability em fundações: Um estudo com fundações privadas da comarca de Ribeirão PRETO-SP. 2007. Dissertação (Mestrado), Programa de Pós-graduação em 0, Robert K. Estudo de Caso: planejamento e métodos. Trad. GRASSI, Daniel. $2^{\mathrm{a}}$ ed. Porto Alegre: Bookman, 2003.

Como citar: HEIM, James Gallinati. HEIM, Suzana Toshimi Furuia Tsukagoshi Gallinati. O sistema de cadastro e prestação de contas como mecanismo da gestão pública nas fundaçções privadas visando transparência administrativas. Revista do Instituto de Direito Constitucional e Cidadania, Londrina, v. 3, n. 2, p. 79-92, jul/dez. 2018. 